\title{
MOOC: Awareness, Participation and Evaluation from China College Students
}

\author{
Ning Wang \\ School of Public administration and politics \\ Hainan University \\ Haikou, China \\ wnin@foxmail.com
}

\author{
Shen Sun \\ School of Public administration and politics \\ Hainan University \\ Haikou, China \\ shensun0610@sina.com
}

\begin{abstract}
MOOC is changing the traditional education. This paper conducted the questionnaire research about what Chinese college students think and how they participate in online distance learning. The data from the questionnaire figures out how MOOC will influence Chinese University students' learning behaviors. According to research results, as emerging studying resources, this paper chooses students as our objective to collect data which is different from existing papers and finds out that MOOC is a powerful tool to bridge the gap between the supply of university and demand of college students.
\end{abstract}

Keywords-MOOC, China College students, learning behavior

\section{INTRODUCTION}

MOOC emerges from U.S.A and rapidly formed a heat worldwide wave, which is a new channel to dissipate knowledge through the online techniques. MOOC provides a low-cost, convenient and borderless knowledge acquisition method, to deconstruct the traditional system of knowledge authority and make the dissemination of knowledge become more flat[1]. Therefore, it is possible to form a multi-center knowledge system. It is an unprecedented mode of knowledge dissemination; therefore, the impact of MOOC for college students' learning behavior is worth exploring.

First, this study focuses on learning cognition, learning process and learning evaluation, and then classifies the college students into certain types, which helps to understand the influence of different MOOC learners' learning behavior. It is different from the existing literature to employ data in which learners leave in the learning process[2]. The influence of MOOC knowledge transmission on Chinese students' behavior is investigated. For the impact of MOOC knowledge transmission on the cognitive process, learning process and evaluation of learning achievement of Chinese college students, the paper uses questionnaire survey method.

The questionnaire includes the basic information of the respondents, the awareness of MOOC, the learning process of MOOC and the evaluation of the situation. The questionnaire uses the Likert scale, which relates to sorting, sequencing and fixed distance data.

The survey issued a total of 2000 questionnaires towards the college students, the effective questionnaires are 1473 copies. The questionnaire was distributed by non-probabilistic sampling and SPSS20.0. In the content validity, the indicators are taken from the well-known indicators which the scholars have repeatedly used and the author made appropriate changes. The questionnaire quality is acceptable and the data structure has reached the requirement of further data processing.

\section{EMPIRICAL RESULT}

\section{A. The basic information of the respondents}

This study cross-analyzes the "personal basic information" and "the understanding of MOOC". It can be considered the understanding of MOOC towards male and female students is of significant difference, because the chi-square statistics are susceptible to the size of the sample, it is necessary to conduct the further correction. Owing to the use of Cramer coefficient test, the Cramer coefficient is less than 0.1, so the relationship between the two is not obvious. The Pearson chi-square data and the Cramer coefficient both indicate that there is no significant correlation between the degree of cognition and the appeal factors of the MOOC in terms of age, school level, educational background, school area and professional subject area.

TABLE I. THE ANALYSIS OF THE BASIC INFORMATION OF THE RESPONDENTS AND THE UNDERSTANDING OF MOOC

\begin{tabular}{|c|c|c|c|}
\hline & $\begin{array}{c}\text { Chi-square } \\
\text { test p value }\end{array}$ & $\begin{array}{c}\text { Cramer test p } \\
\text { value }\end{array}$ & $\begin{array}{c}\text { Significant } \\
\text { differences(Yes or no) }\end{array}$ \\
\hline Gender & 0.022 & 0.07 & No \\
\hline Age & 0.288 & 0.058 & No \\
\hline School level & 0.909 & 0.026 & No \\
\hline Academic level & 0.129 & 0.062 & No \\
\hline School location & 0.943 & 0.009 & No \\
\hline $\begin{array}{c}\text { Professional } \\
\text { disciplines }\end{array}$ & 0.576 & 0.027 & No \\
\hline
\end{tabular}

From the gender aspect, Pearson chi-square data is 0.022 , Cramer coefficient is less than 0.1, the relationship between the two is not obvious; from the age distribution of the survey respondents, the subjects were aged between 15 and over 30 years, the relationship between the age of learners and the understanding of MOOC is not significant, the courses provided by MOOC meet the learning needs of different ages; from the school level, with the chi-square test, it's concluded that there is no significant positive correlation between these 
two factors. MOOC emphasizes the "open" way of knowledge transmission for different levels of college students, which provides an equal opportunity to share quality education resources, MOOC is more like a free and open knowledge market, not only high-level college students can learn or use MOOC; from the level of education, it is clear that the use of chi-square test shows the significance level is higher than 0.05, so that the relationship between the degree of MOOC and the level of degree education can be clearly seen there is no significant correlation. MOOC platform provides a wide range of courses types, covering widely, students with different degrees in the MOOC platform can find suitable courses; from the school perspective, the geographical factors' influence on whether understanding MOOC or not is not significant, however, it is necessary to combine the current situation of Chinese universities and colleges, and analyze the regional level, and then make a contingency table analysis of the regional and school level and the degree of understanding of MOOC. There is no significant difference in the degree of understanding of MOOC students in the eastern, central, western and different regions of different schools. Therefore, MOOC can be considered to make education to a certain extent overcome the geographical and school level constraints; from the learners' subject perspectives, considering the early introduction of science courses, the corresponding to attract more professional background students to register to study, therefore, classifying and exploring the professional background of the learners. A more interesting phenomenon is that there is no significant relationship between the MOOC course and the subject area. At the same time, part of the MOOC course on the university in China is a part of the lower interest class, which is biased towards humanities and social sciences and may attract more students studying social science and humanities.

On the basis of overall data analysis ideas, we start exploring college students' traditional learning behavior. Because the questionnaire itself does not involve the time series, and students who have entered MOOC may choose more MOOC courses, therefore, it may have an impact on the results of this study.
TABLE II. THE LEARNING BEHAVIOR OF THE RESPONDENTS WHO DO NOT KNOW MOOC

\begin{tabular}{|c|c|c|c|}
\hline Variable & Category & Number of people & $\begin{array}{c}\text { Effective } \\
\text { percentage } \%\end{array}$ \\
\hline \multirow{4}{*}{$\begin{array}{l}\text { The main } \\
\text { way to } \\
\text { acquire } \\
\text { knowledge }\end{array}$} & Literature review & 493 & 76.9 \\
\hline & Lecture & 44 & 6.9 \\
\hline & $\begin{array}{l}\text { Academic } \\
\text { conference }\end{array}$ & 10 & 1.6 \\
\hline & MOOC & 94 & 14.7 \\
\hline \multirow{3}{*}{$\begin{array}{l}\text { The main } \\
\text { way of } \\
\text { completing } \\
\text { learning } \\
\text { tasks }\end{array}$} & Personal learning & 575 & 89.7 \\
\hline & Group learning & 27 & 4.2 \\
\hline & Campus association & 39 & 6.1 \\
\hline \multirow{5}{*}{$\begin{array}{l}\text { The } \\
\text { initiative } \\
\text { degree of } \\
\text { completing } \\
\text { learning } \\
\text { tasks }\end{array}$} & passive & 77 & 12.0 \\
\hline & Relatively passive & 175 & 27.3 \\
\hline & Ordinary & 259 & 40.4 \\
\hline & Relatively active & 105 & 16.4 \\
\hline & Active & 25 & 3.9 \\
\hline \multirow{5}{*}{$\begin{array}{l}\text { The } \\
\text { understandi } \\
\text { ng degree of } \\
\text { the network } \\
\text { course }\end{array}$} & Do not understand & 195 & 30.4 \\
\hline & Less understanding & 139 & 21.7 \\
\hline & Ordinary & 256 & 39.9 \\
\hline & $\begin{array}{c}\text { Comparative } \\
\text { understanding }\end{array}$ & 42 & 6.6 \\
\hline & Understand & 9 & 1.4 \\
\hline \multirow{5}{*}{$\begin{array}{l}\text { The } \\
\text { satisfaction } \\
\text { degree of } \\
\text { online } \\
\text { courses }\end{array}$} & satisfied & 46 & 7.2 \\
\hline & $\begin{array}{l}\text { Comparatively } \\
\text { satisfied }\end{array}$ & 73 & 11.4 \\
\hline & Ordinary & 413 & 64.4 \\
\hline & Less satisfied & 93 & 14.5 \\
\hline & Not satisfied & 16 & 2.5 \\
\hline
\end{tabular}

The learning style of the students who don't know MOOC can be summarized as the understanding of the network course is general or is not very satisfying for the web course with the relatively low initiative to learn the passive mode of learning. The characteristics of this part of the students are at variance with students who meet MOOC requirements such as studentcentered, online learning interaction, based on the network technology, distributed learning process and so on.

From the intuitive data analysis, it can be found that Chinese college students' awareness and understanding of MOOC is low. And the reason needs to be further explored. Obviously, this situation is not conducive to MOOC development in the country, and is not conducive to the impact of student learning behavior as well. 
TABLE III. BEFORE MOOC, THE CORRELATION ANALYSIS OF THE LEARNING INITIATIVE, THE UNDERSTANDING DEGREE OF NETWORK CURRICULUM AND THE SATISFACTION DEGREE OF NETWORK COURSES

\begin{tabular}{|c|c|c|c|}
\hline & $\begin{array}{c}\text { Learning } \\
\text { initiative }\end{array}$ & $\begin{array}{c}\text { Understanding } \\
\text { degree of } \\
\text { network courses }\end{array}$ & $\begin{array}{c}\text { Satisfaction degree of } \\
\text { network courses }\end{array}$ \\
\hline $\begin{array}{c}\text { Spearman } \\
\text { coefficient }\end{array}$ & 0.119 & 0.258 & 0.123 \\
\hline $\begin{array}{c}\text { Sig. two- } \\
\text { sided test p } \\
\text { value }\end{array}$ & 0.000 & 0.000 & 0.000 \\
\hline
\end{tabular}

TABLE IV. BEFORE CONTACTING WITH MOOC, THE SIGNIFICANTLY DIFFERENCE BETWEEN THREE PROBLEMS AND MOOC

\begin{tabular}{|c|c|c|c|}
\hline Variable & Category & $\begin{array}{c}\text { Number of } \\
\text { people }\end{array}$ & Effective percentage \% \\
\hline \multirow{4}{*}{$\begin{array}{l}\text { Length of } \\
\text { contact with } \\
\text { MOOC }\end{array}$} & $\begin{array}{c}\text { Less than } 3 \\
\text { months }\end{array}$ & 536 & 64.4 \\
\hline & 3-6 months & 133 & 16 \\
\hline & 6-12 months & 85 & 10.2 \\
\hline & $\begin{array}{l}\text { More than } 12 \\
\text { months }\end{array}$ & 78 & 9.4 \\
\hline \multirow{4}{*}{$\begin{array}{l}\text { Number of } \\
\text { registered } \\
\text { MOOC }\end{array}$} & Not registered & 431 & 51.8 \\
\hline & $1-2$ courses & 285 & 34.3 \\
\hline & 3-4 courses & 74 & 8.9 \\
\hline & Above 4 courses & 42 & 5 \\
\hline \multirow{5}{*}{$\begin{array}{c}\text { How many } \\
\text { courses have } \\
\text { been completed } \\
\text { in MOOC }\end{array}$} & All unfinished & 315 & 37.8 \\
\hline & $\begin{array}{l}\text { Basically not } \\
\text { completed }\end{array}$ & 187 & 22.5 \\
\hline & commonly & 189 & 22.7 \\
\hline & $\begin{array}{l}\text { Basically } \\
\text { completed }\end{array}$ & 81 & 9.7 \\
\hline & All completed & 60 & 7.2 \\
\hline \multirow{4}{*}{$\begin{array}{l}\text { The number of } \\
\text { learning MOOC } \\
\text { at the same time }\end{array}$} & 1 course & 557 & 66.9 \\
\hline & 2 courses & 202 & 24.3 \\
\hline & 3 courses & 38 & 4.6 \\
\hline & Above 3 courses & 35 & 4.2 \\
\hline \multirow{5}{*}{$\begin{array}{l}\text { Weekly schedule } \\
\text { to study MOOC }\end{array}$} & $0-1$ hours & 422 & 50.7 \\
\hline & 1-2 hours & 197 & 23.7 \\
\hline & 2-3 hours & 120 & 14.4 \\
\hline & 3-4 hours & 58 & 7.0 \\
\hline & $\begin{array}{l}\text { More than } 4 \\
\text { hours }\end{array}$ & 35 & 4.2 \\
\hline
\end{tabular}

The degree of pre-learning activity of MOOC, the understanding of network course and the satisfaction degree of network course were extracted, and the related degree of MOOC understanding was analyzed. Since all of them are ordinal variables, the Spielman coefficient is used to test, and the three problems have a significant difference with MOOC(Sig. $=0<0.05$ ), and there is a certain correlation (Spearman coefficient $>0.1$ ).
Learners in the traditional learning need a certain degree of autonomy, and they can gain more knowledge or information in online education or MOOC platform. Students who are active on learning are easier to understand MOOC, which is similar to MOOC's own emphasis on active features. MOOC requires learners have a high degree of self-awareness and selfcontrol ability, not all learners are suitable for MOOC learning model. All in all, the students who have learned more about the web course are generally more aware of MOOC's new network platform. MOOC also unconsciously experiences Unicomism which Simmons's emphasis on, that is the traditional static, classification and hierarchical knowledge dissemination paradigm for the development of information network field under the dynamic network of knowledge flow. Learning is mainly in the process of forming a knowledge node in a dynamically linked knowledge network.

\section{B. The forms and preferences of participation in MOOC}

In the study of traditional student learning behavior, the traditional paper-based learning mode dominates. Although some contact with online courses or online education, its lack of understanding makes the students difficult to continue indepth study. According to the respondents which have a certain understanding of MOOC, the data shows that MOOC shapes their learning behavior from different angles. It can also be seen from the results of the data analysis that the impact on them is more positive and that the change in the learning behavior is preserved, which has a profound and lasting effect on the learner's learning behavior.

According to the contingency table analysis between selecting the type of MOOC course and weekly arrangements of study MOOC, through the test, the Pearson chi-square $\mathrm{p}$ value of 0.000 , initially shows that the difference between the two is significant. Since the chi-square estimator is susceptible to the size of the sample, it needs to be verified by the Cramer coefficient. Since the Cramer coefficient v is 0.52 , close to 1 , it means the two have a strong correlation.

TABLE V. CORRELATION ANALYSIS OF TASK COMPLETION AND OTHER FACTORS

\begin{tabular}{|c|c|c|c|}
\hline & $\begin{array}{c}\text { P two-sided } \\
\text { test }\end{array}$ & $\begin{array}{c}\text { Spearman } \\
\text { coefficient }\end{array}$ & $\begin{array}{c}\text { Correlation } \\
\text { strength }\end{array}$ \\
\hline $\begin{array}{c}\text { Satisfaction degree of } \\
\text { online discussion }\end{array}$ & 0 & 0.503 & $\begin{array}{c}\text { Moderately } \\
\text { correlated }\end{array}$ \\
\hline $\begin{array}{c}\text { Understanding degree of } \\
\text { teaching content }\end{array}$ & 0 & 0.444 & $\begin{array}{c}\text { Moderately } \\
\text { correlated }\end{array}$ \\
\hline $\begin{array}{c}\text { Satisfaction degree of } \\
\text { teaching content }\end{array}$ & 0 & 0.424 & $\begin{array}{c}\text { Moderately } \\
\text { correlated }\end{array}$ \\
\hline
\end{tabular}

As can be seen from the data in TABLE V, the various learning times are the largest in interested courses. It can be seen that most MOOC learners tend to study interested courses. MOOC learners whose study MOOC schedule spends 0-1 hours every week, learners are called potential learners. MOOC breaks the time and space constraints of knowledge learning and offers the opportunity to study elite courses, but most learners' task completion and spiritual concentration still need to be improved. Therefore, MOOC knowledge transmission mode needs to go through a step-by-step process, so that 
learners gradually enhance the awareness of independent learning, and adapt to the way of knowledge dissemination.

Choosing different types of courses in the MOOC platform can directly affect the factors that are scheduled for weekly time during the MOOC platform learning process, such as the number of MOOC courses, the completion of the course tasks, and the concentration of the focus in the learning process. All variables are treated as fixed-length variables. It can be seen that the number of MOOC courses at the same time has the greatest impact on the weekly study time, but the effect on the degree of completion of classroom tasks and the concentration of energy is relatively weak, and the breadth of MOOC learning is wider, while the curriculum design or other related factors need to be further explored.

It can be seen that the surveyed object is devoted to the breadth of the MOOC platform rather than the depth of the study, which is consistent with the choice of course for most people. Choosing the interested course, tinkering with the time, the investment can come from learning more courses, rather than a course of digging. It is difficult to replace the core curriculum or professional related courses, which may also the reasons why it is more difficult to promote MOOC in China. Continuing to check the completion of MOOC, according to the relationship between the type of MOOC program and the completion of the registration course, it was found that the type of course was related to the type of registration course (Pearson chi-square $\mathrm{p}$ value was 0.000 , Cramer coefficient $\mathrm{V}$ value was 0.517 ). Combined with the established model, we can know that the respondents for the choice of the curriculum showed a heavy and uneven performance, and most selected courses are interested courses. The surveyed subjects were mainly engaged in online education, $44.0 \%$ were completed in the classroom, $45.8 \%$ of the respondents were interested in choosing courses. They tend to expand MOOC as a platform for classroom education or as a platform to find interested courses. Compared to the more basic course content of domestic online courses, MOOC offers a wider range of courses. From the point of view of the course selection, the course selection is heavy, not redepth, more inclined to continue to try different courses. For a course lack of deep plowing, it can be seen from the time investment model that the increase in time is mainly due to the increase in the number of courses chosen at the same time. It can be considered that the respondents who use MOOC, they do not form a complete and clear plan of how to use it. MOOC has not become one of the core ways to acquire knowledge.

At the same time, using the contingency table to do correlation test of selecting the number of courses and learning time, we can find that from the group analysis results by testing, Preason chi-square test $\mathrm{p}$ value of 0.000 , Cramer coefficient V value of 0.597 , we can confirm the learning time and selection courses have strong correlation. Next, through the analysis, we found that students choose one course, weekly arrange less than 2 hours to learn MOOC course, and the actual value is higher than the expected value. With the simultaneous increase in the number of courses, the trend appeared to reverse. Students who study longer are expected to be higher, while students learning MOOC courses more prefer MOOC courses to some extent, their own internal motivation is also stronger, fully demonstrating MOOC as online education platform is more dependent on the characteristics of student autonomy.

In addition, according to the contingency table analysis of course selection and the school level, the chi-square test value is 0.015 , Cramer coefficient $\mathrm{V}$ value is 0.1 . According to the chi-square test values are less than 0.05 , Cramer coefficient V value greater than 0.1 , it can be considered that there is a significant correlation between school level and curriculum choice. Through the analysis of the contingency table and the double bar graph, it is found that the school level and the choice of the course, colleges and universities which are relatively concentrated in the educational resources such as "985" and "211" level and so on, the interest is lower than that of ordinary colleges and universities from the professional courses or professional courses on MOOC, but it is of great interest to the interested course. Ordinary students are relatively average for the distribution of curriculum choices, but relatively large proportion of students chooses core courses and professional courses. It may also reflect the relative lack of teaching resources, and the purpose to make up the trend through this channel.

\section{Evaluation of MOOC learning}

The non-parametric test of multi-independent samples is used to explore the reasons of the plan to be promoted after MOOC study. Here, the rate of ascension as a categorical variable, the paper introduces two factors to analyze: the weekly schedule and the task completion. From the above tables, the median values respectively are 1 and 3, that is, time within 1 hour, the task completion degree is general, the significance is less than 0.05 and the frequency is greater than 5. We can adopt this conclusion. KW test and JT test of the significance of the level are less than 0.05 , which can be considered in the study of MOOC there are significant differences in learners' learning ability in the process of learning MOOC. After the end of MOOC learning, it can be concluded that the input of time is more important to the students' learning behavior; to select the task completion degree as a measure of whether to meet the learners demand index, generally speaking, the premise of the completion of the task of the course is to acquire knowledge more efficiently in the learning process. Spending more time can more effectively meet the needs of knowledge learning. The non-parametric test of multi-independent samples is used to classify the classroom tasks. The test variables are: online interaction and Q\&A satisfaction degree, the degree of understanding of MOOC course content and the degree of satisfaction with MOOC course content. Significant levels were found to pass the test; it can be considered that there are significant differences in the evaluation of the learning effects of different levels of task completion. But the expected frequency is less than 5, this conclusion can only be used as a reference. Through the K-W test and J-T test, we found that the significance level passed the test, the conclusion is more reliable. With the students' understanding of the course content, the degree of satisfaction and the degree of satisfaction of online Q \& A discussion, the completion of the task of the curriculum is also improved.

The higher the degree of completion of learners' tasks, the greater the degree of improvement in learning behavior 


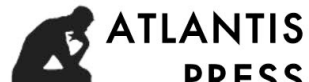 PRESS}

(bilateral test $\mathrm{p}$ value, Spearman coefficient is 0.434 , belonging to the medium correlation and positive correlation).

The results showed that the time of exposure to MOOC has significant correlation with the number of registered MOOC courses. The $\mathrm{P}$ value was less than 0.05 , and the correlation coefficient was 0.538 , which could be considered as a positive correlation with moderate intensity. The time interval of the contact time is set according to the completion time of a course that is 3 months. It can be inferred that the the learner contacts with MOOC longer, the chance to register more courses corresponding to is greater, then, we found that with the extension of the MOOC course time, registration courses are also increasing, but most people contact time is mainly concentrated in the three months and below, most students also did not choose to register MOOC course, which may be related with the MOOC demand positioning. Part of the students for the MOOC positioning is to consolidate the course of knowledge of the new means and tools, regardless of the fact that their own registration courses or courses are of no potential demand.

Further explore whether real difficulties will lead students to abandon MOOC courses. Select "the primary reasons of students giving up the course" and "the course which has been completed " for analysis, make analysis on the completion rate and Realistic deficiency to see whether the students will have an impact on the registration process. According to the results of the test, the chi-square test p-value is 0.003, Cramer coefficient $\mathrm{V}$ value is 0.109 , the significance level through the test, according to the analysis results, we can see, regardless of MOOC course completion rate, insufficient learning time will make students not able to complete the relevant tasks and the expansion of learning are the primary cause. That they haven't learned the relevant course content which led to inexperienced learning is the secondary reason. In the four cases in which the completion rate is "all unfinished", "basic unfinished", "normal" and "basically finished", the difference between the primary and secondary causes are very large, more than doubling. And in the case of all completion, the gap between the two is not obvious. And these two results reflect two phenomena: the difficulty of MOOC course makes some college students not able to understand so that they can't adhere to learning; course selection is unreasonable and improper learning time, which make the course too difficult and students have insufficient time to complete the course assignments or extend learning so that they give up MOOC courses.

MOOC's own inherent limitations limit the choice of students and the student's own problem with the arrangement of time. The pressure from outside the network makes the students lean on the "comfort zone" in the face of choice to abandon learning MOOC. The process of transforming knowledge into skills requires a lot of time, and it is not surprising that learners have made a choice to abandon the MOOC after a certain amount of judgment and measurement, under the pressure of no external time.

The difference between the learners' choice of course type and the degree of improvement of the learning plan ability is analyzed. The Pearson bilateral test has a p value is 0.001 and a
Cramer coefficient is 0.117 . According to the analysis results, MOOC study after the end of their own learning plans to significantly develop ability to improve the relationship. The proportion of selected courses was 54.3\% and 43.2\%, respectively, among the learners with significant improvement in the ability to develop programs and basic improvement. This is understood by the fact that most of the students who are planning to develop their abilities are more likely to learn more about the course of interest. The degree of understanding of the course does not pose a great challenge, and the interested course is more discretionary and more dependent on the time of the local specific circumstances. The overall timing of the request is not high. And secondly, the choice of core courses or professional courses related to the students may be doing extracurricular expansion or learning of MOOC in review, time investment and specific. The completion of the course requires the learner to plan the time reasonably. After a long period of study, the ability to develop a plan has been improved.

In the above analysis of the learning process and the degree of understanding of the MOOC in the questionnaire on the learning process analysis and exploration, it can be clearly seen that for people who have deeper understanding degree of MOOC, they will have higher degree of participation in the MOOC learning process. Correspondingly, the evaluation of learning outcomes is more positive and they will more discover the potential value of MOOC. This conclusion and MOOC "designed for learning" concept have a great relationship. In the "better understanding" of MOOC and above level, the learning behavior shows the largest change, the MOOC platform resources are the most adequate. This is related to MOOC's emphasis on crowd-sourced interaction in its learning style. MOOC uses the forums, assistant feedback and other online interactive way to participate in the study of students from the knowledge provider and the interaction between the learners to provide two dimensions of the learning process to solve the problem mechanism. Although its transaction costs are very low, its entry threshold is very high in the existing conditions. Subject to the objective conditions and subjective factors, MOOC learning is more similar to the "club" products, which needs to rely on their own initiative, enthusiasm, etc. to understand the MOOC. With the improvement of the MOOC understanding degree, and gradually enhance their understanding of the MOOC, and get more knowledge, and accordingly, more active students, can we pay a very low "transaction costs" to get more relevant knowledge to complement, so as to get more satisfaction, and the corresponding satisfaction with the MOOC appears to rise. Here, MOOC has played a role as a screening mechanism for students who really need knowledge from this channel to provide access to free access to knowledge, as well as low-cost opportunities for students with similar needs.

In addition, for the reason of abandoning the MOOC study, $53.7 \%$ of the respondents selected the "lack of learning time", while $18.9 \%$ of the respondents selected "did not repair the relevant courses so that can't be in-depth study." $17.3 \%$ of the respondents selected the "poor network". 


\section{CONCLUSION}

1. The emergence and development of MOOC is based on the "free market" mechanism, which is a basic contradiction with the traditional highly regulated higher education system. The traditional passive learning is gradually replaced by active learning. "Cramming" knowledge is gradually replaced by active learning which is based on need; learning evaluation based on knowledge will change gradually, learning evaluation based on traditional authority has gradually developed into the evaluation mechanism based on mutual authentication.

2. MOOC as a kind of knowledge communication technology is affecting the students' learning style. Chinese universities as a distribution center of the high-level knowledge of the production and dissemination, their knowledge structure is systematic, institutionalized, authoritative and professional. Knowledge has certain homogeneity, may encounter some difficulties in the process of knowledge creation, and can't meet the requirements of the MOOC learning process. How to change the traditional way of knowledge transmission is a new topic in front of the university after the appearance of MOOC.
3. MOOC as an "exotic" thing with the advantages of knowledge dissemination has been no longer repeated, but from the evaluation of participation in MOOC learning, the evaluation of Chinese college students is not as positive as the evaluation made by the researchers. This is due in part to the fact that MOOC learners are not getting enough incentive to learn, such as credits, education and so on, and there is not a lot of time devoting to the MOOC study; second, Chinese knowledge market is not an open market, learners do not have enough knowledge resources to choose.

\section{REFERENCES}

[1] Foucault M, “The Subject and Power”, Critical inquiry, 1982, 8(4): 777795.

[2] Breslow, L., Pritchard, D. E., DeBoer, J., Stump, G. S., Ho, A. D., \& Seaton, D. T. Studying Learning in the Worldwide Classroom: Research into edX's first MOOC. Research \& Practice in Assessment, 2013(8):1325.

[3] Ning Wang. Educaton Policy: Subjective Value Analysis. Beijing:China Social Science Press,2013, p22. 